\title{
Urban Studies By Using Remote Sensing And Geographical Information System
}

\author{
Sureshkumar $\mathbf{M}^{1}$, Sai Kalyan ${ }^{2}{ }^{2}$, Vinay Kumar MVNS ${ }^{3}$ \\ 1,2,3 Department Of Civil And Structural Engineering, SCSVMV Enathur, Tamil Nadu, India \\ Email:Sureshgis@Kanchiuniv.Ac.In
}

\begin{abstract}
The development and utilization of smart cities are essential due to the technological growth and fulfilling the present urban situation. Now it is the time for smart city as like smart phones, smart watches, smart band, even smart home etc. By using remote sensing and Geographical Information System (GIS) a spatial digital map has been prepared. The result from this project may act as a supporting document for proper planning of Kanchipuram as smart city.
\end{abstract}

Keywords: Smart city, GIS, GPS, Urban Studies

\section{INTRODUCTION}

Being smart city, smart pole is essential for various roles [1]. A spatial based smart pole location in the city has been identified by considering various conditions which include CCTV surveillance.

The city requires smart transits facility, where the roads are busy at some times, GIS based alternate route map has been prepared for smart transit facility in Kanchipuram. Due to increase in vehicle count, smart parking is essential for the city, it has been identified where and all the space is less for parking vehicles in the city [2-3]. To overcome the present parking congestion, some spatial locations with suitable methods are suggested. Thematic maps are prepared for the water bodies for proper maintaining and to avoid encroachment. The outcome of the project suggests various necessary spatial data for the Kanchipuram.

\section{MATERIALS AND METHODS}

\subsection{Smart pole}

The Smart Pole is a Smart Product, which uses MPS technologies embedded by using steel and aluminum poles for public safety, anti-theft, crime prevention, surveillance, anti-terrorism and numerous lighting applications. The Smart Pole can be manufactured by the specific requirements which we needed. Each Smart Pole can be custom built to your particular requirements. Smart pole location requirement in Kanchipuram city has been identified and shown in Fig.1.

The smart poles are evenly placed entire Kanchipuram such that it covers maximum most of the area and important tourist's places. The distance between two smart poles is in between 600-800 meters depending upon the locality and the population over that area. This smart pole technology not only user friendly but also provides secured system to entire city. This really helps to knock out emergency situations.

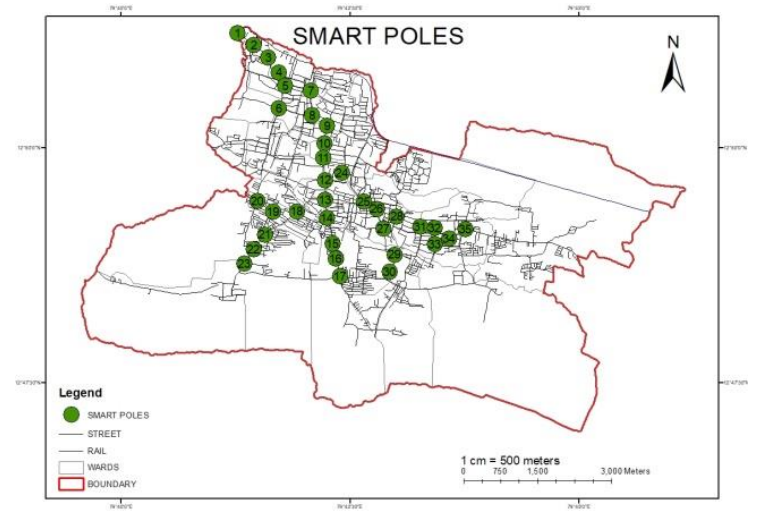

Fig.1 Smart Pole Location Map

\subsection{Smart Parking}

Nowadays as population is increasing the usage of vehicles are also increased. so the place at the public places and private places is not sufficient and thereby we are going to adopt this technique and also this is one of the smart city concept to develop the city [4]. The main theme of this concept is to save the land as the land nowadays is very less and the same way we can use that land for other things by this the owner also no need to invest more money on parking area alone. The spatial location mentioned in Fig.2 indicates the location where smart parking service is required in the city [5].

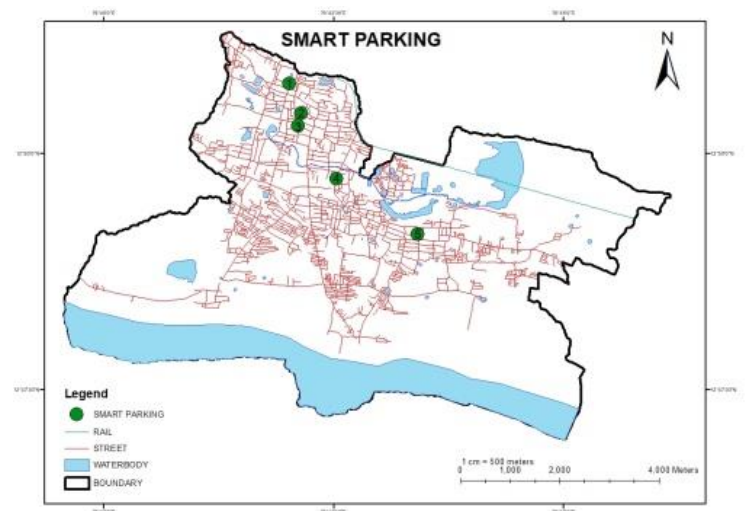

Fig.2 Smart Parking Location Map

\subsection{Smart Transit}

Smart transit is an advanced method which aims to provide innovative services relating to different modes 


\section{Available online at $w w w . i j r a t . o r g$}

of transport and traffic management and enable users to be better informed and make safer, more coordinated, and smarter use of transport network [67]. Smart transit system includes in systems such as car navigation, traffic signal control system, speed cameras to monitor applications, and more advanced technology to integrate live data and feedback from a number of other sources, such as parking guidance, weather information systems.

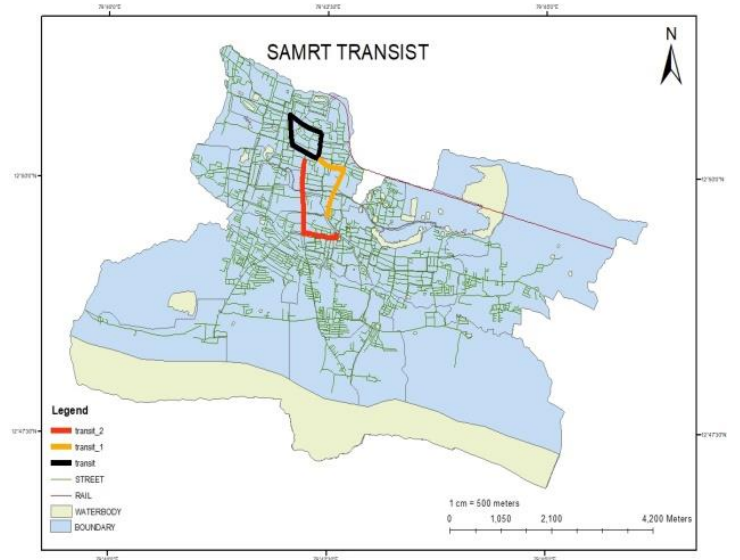

Fig.3 Smart Transit Map

There are some particular places in Kanchipuram city where the traffic is extremely high in peak times during the day [8]. In order to overcome this something must be implemented, so that the traffic can be managed. In Fig.3, an alternate route map has been shown for proper managing the transit service in Kanchipuram [9].

\section{RESULT AND CONCLUSION}

The project suggests the utilization of GIS tool for proper smart city planning and management. The smart parking, smart pole and smart transit spatial map helps to understand the city. Based on the prepared thematic map, it is possible to implement the above studied features. The outcome of this work may be useful to the town planning and local authorities for ease city management.

\section{ACKNOWLEDGMENTS}

The authors also wish to record a deep sense of gratitude to SCSVMV, Enathur, Kanchipuram, Tamil Nadu, India. The authors also wish to record a deep sense of gratitude to Dr.N.Seshadri Sekhar, HOD, Department of Civil \& Structural Engineering, SCSVMV for constant support to complete the project.

\section{REFERENCES}

[1] Persai, Prashant, and Sunil Kumar Katiyar. "Development of Information Evaluation System for Smart City Planning Using Geoinformatics Techniques." Journal of the Indian Society of Remote Sensing 46.11 (2018): 1881-1891.
[2] Šilar, Jan, et al. "Smart parking in the smart city application." 2018 Smart City Symposium Prague (SCSP). IEEE, 2018.

[3] Wang, Zi-Jia, Yan Liu, and Feng Chen. "Evaluation and Improvement of the Interchange from Bus to Metro Using Smart Card Data and GIS." Journal of Urban Planning and Development 144.2 (2018): 05018004.

[4] Nour, Akram, Bruce Hellinga, and Jeffrey Casello. "Classification of automobile and transit trips from Smartphone data: Enhancing accuracy using spatial statistics and GIS." Journal of Transport Geography 51 (2016): 36-44.

[5] Shaw, Shih-Lung. "GIS for Transportation." International Encyclopedia of Geography: People, the Earth, Environment and Technology: People, the Earth, Environment and Technology (2016): $1-9$

[6] Sun, Daniel, et al. "A bus route evaluation model based on GIS and super-efficient data envelopment analysis." Transportation Planning and Technology 39.4 (2016): 407-423.

[7] Main, Eric V. "Using GIS and Python for Assessment and Prioritization of Potential Transit Projects." (2016).

[8] Wiewel, Wim, and Gerrit Knaap. "Using a Geographic Information System (GIS) to Help Shape Redevelopment of Small Urban Centers." Partnerships for Smart Growth: UniversityCommunity Collaboration for Better Public Places. Routledge, 2017. 93-104.

[9] Chen, Shichao, et al. "The Smart Street Lighting System Based on NB-IoT." 2018 Chinese Automation Congress (CAC). IEEE, 2018. 